\title{
BYZANTINO-SLAVIC AND BULGARIAN MIDDLE AGES IN THE RECENT WORKS BY SCHOLARS FROM THE UNIVERSITY OF LODZ
}

\author{
Dmitry I. Polyvyannyy \\ Ivanovo State University, Ivanovo, Russian Federation
}

\begin{abstract}
The review considers the recent works by Polish academicians from two departments of the University of Lodz - History of Byzantium and Slavic Philology dedicated or related to the history and culture of medieval Bulgaria and the entire Byzantino-Slavic community of the $10^{\text {th }}-15^{\text {th }} \mathrm{c}$. aiming to represent them to Russian audience, to reveal their contributions to the mentioned fields and to appreciate the current achievements of the forming academic school of the University of Lodz. Its beginning cannot be divided from the name of the disciple of prominent Polish Byzantinist Professor Halina Ewert-Kappesowa (1904-1985), Professor Waldemar Ceran (1936-2009), whose research and organizational activities led to the establishment of "Byzantina Lodziensia" book series (39 volumes published in 1997-2020), and in 2003 - to the Department of the History of Byzantium opening. These foundations met resonance and support from a new trend of the research activities in the University of Lodz - Old Slavonic literature studies - initiated by highly skilled paleoslavist Professor Georgi Minczew who began his work at the Department of Slavic Philology in the middle of the 1990s. The growing synergy of the Byzantine and Slavic trends resulted in the creation in 2011 of Ceraneum - the Centre of Research in History and Culture of Mediterranean and South-Eastern Europe named after W. Ceran (Centrum Badań nad Historią i Kulturą Basenu Morza Śródziemnego i Europy Południowo-Wschodniej im. prof. Waldemara Cerana, Ceraneum). Under its aegis the University of Lodz is editing annual scholarly journal "Studia Ceranea" (10 issues in 2011-2020) and since 2019 convenes in the historical venue of Bidermann Palace, the residence of the centre, annual international colloquium "Colloquia Ceranea" which attracts leading Polish and international scholars in Byzantine, Slavic and Bulgarian medieval history and culture. The author critically reviews monographs and miscellanies published by academicians of the University of Lodz in the recent five years and concludes upon the main research directions, results and perspectives of the University of Lodz school of Byzantine, Medieval Slavic and Bulgarian research.

Key words: Middle Ages, Byzantium, Slavs, Bulgaria, University of Lodz, Waldemar Ceran, Georgi Minczew.

Citation. Polyvyannyy D.I. Byzantino-Slavic and Bulgarian Middle Ages in the Recent Works by Scholars from the University of Lodz. Vestnik Volgogradskogo gosudarstvennogo universiteta. Seriya 4. Istoriya. Regionovedenie. Mezhdunarodnye otnosheniya [Science Journal of Volgograd State University. History. Area Studies. International Relations], 2020, vol. 25, no. 6, pp. 305-316. (in Russian). DOI: https://doi.org/10.15688/ jvolsu4.2020.6.25
\end{abstract}

УДК 94 “04/14”:930

Дата поступления статьи: 01.07.2020

ББК 63.3(0)4г

Дата принятия статьи: 17.07.2020

\section{ВИЗАНТИЙСКО-СЛАВЯНСКОЕ И БОЛГАРСКОЕ СРЕДНЕВЕКОВЬЕ В НОВЕЙШИХ ТРУДАХ УЧЕНЫХ УНИВЕРСИТЕТА ЛОДЗИ}

\section{Дмитрий Игоревич Полывянный}

Ивановский государственный университет, г. Иваново, Российская Федерация

Аннотация. В обзоре рассматриваются новейшие работы польских ученых двух кафедр Лодзинского университета - истории Византии и славянской филологии, посвященные или касающиеся истории и культуры средневековой Болгарии и всей византийско-славянской общности X-XV вв., с целью представить их российской аудитории, раскрыть их вклад в исследование указанных областей и оценить текущую деятельность развивающейся в Лодзи научной школы и ее перспектив. Ее начало неотделимо от имени ученика выдающего польского византолога Халины Эверт-Каппесовой (1904-1985), профессора Вальдемара Церана 
(1936-2009), чьими усилиями было начато издание Лодзинским университетом серии «Вуzantina Lodziensia» (в 1997-2020 гг. опубликованы 39 томов) и в 2003 г. была открыта кафедра истории Византии. Эти начинания нашли отклик и поддержку еще одного, нового тренда исследовательской деятельности университета - изучения средневековой литературы и фольклора православных славян - во главе с высококвалифицированным палеославистом, получившим всестороннюю подготовку в Софийском университете Георгием Минчевым, который начал работу на кафедре славянской филологии в середине 1990-х годов. Растущая синергия византийского и славянского направлений выразились в создании в 2011 г. Центра исследований истории и культуры средиземноморского бассейна и Юго-Восточной Европы имени профессора В. Церана или Церанеума (Centrum Badań nad Historią i Kulturą Basenu Morza Śródziemnego i Europy Południowo-Wschodniej im. prof. Waldemara Cerana, Ceraneum). Под его эгидой Лодзинский университет издает научный ежегодник «Studia Ceranea» (в 2011-2020 гг. опубликовано 10 томов), а с 2019 г. проводит международный научный коллоквиум “Colloquia Ceranea”, привлекающий в исторический интерьер особняка Бидерманна - резиденции Центра ведущих польских и зарубежных ученых в области византийской, средневековой славянской и болгарской истории и культуры. Автор критически аннотирует монографии и сборники научных трудов лодзинских ученых в этих областях, изданные в последние пять лет, делая выводы об основных достижениях ученых Лодзинского университета в этих областях, о направлениях и перспективах дальнейших исследований.

Ключевые слова: Средние века, Византия, славяне, Болгария, Лодзинский университет, Вальдемар Церан, Георгий Минчев.

Цитирование. Полывянный Д. И. Византийско-славянское и болгарское средневековье в новейших трудах ученых университета Лодзи // Вестник Волгоградского государственного университета. Серия 4, История. Регионоведение. Международные отношения. - 2020. - T. 25, № 6. - С. 305-316. - DOI: https://doi.org/ 10.15688/jvolsu4.2020.6.25

Введение. Становление локальной научной школы, как правило, заметно с выходом в академическую науку третьего поколения воспитанных в ее лоне ученых, которые сознают значение традиций, заложенных их предшественниками, и способны их достойно продолжить и развить. Корни заявившей о себе в начале нынешнего века Лодзинской школы византийско-славянских исследований прочны и глубоки. Ее историю следует начать с трудов Халины Эверст-Каппесовой (1904$1985)$ - одной из первых польских ученых-византологов и ученицы основателя кафедры истории Византии Варшавского университета профессора Казимежа Закжевского (19001941), погибшего от рук нацистов. Х. ЭверстКаппесова с 1950 г. работала в Лодзинском университете, открыв в 1957 г. отделение истории Византии, где в 1960 г. начал свою академическую карьеру ее ученик и продолжатель Вальдемар Церан (1936-2009). В. Церану принадлежит заслуга создания в Лодзинском университете кафедры истории Византии (2003), объединившей его учеников, включая его преемника на заведовании кафедрой проф. Мачея Кокошко.

Основанная В. Цераном в 1997 г. серия «Byzantina Lodziensia», публикуемая издательством Лодзинского университета, сейчас на- считывает 39 томов, среди которых - составленная В. Цераном двухтомная аннотированная библиография трудов польских исследователей истории Византии [7]. Первым в этой серии трудом по византийско-славянской тематике была монография ученика В. Церана Мирослава Лешки об образах государей первого Болгарского царства в византийских письменных источниках VIII - первой половины XII века [8]. Десятилетие спустя профессор М. Лешка продолжил византийско-болгарское направление книгой о болгаро-византийских отношениях в правление Симеона [9], а затем - написанной в соавторстве с Зофьей Бжозовской монографией о болгарской царице Марии-Ирине Лакапине (927-953), «ни святой, ни злодейке» [5]. Содержание исследования вошло в изданную в Лодзи на английском языке коллективную монографию «Болгарское государство в 927-969 гг. Эпоха болгарского царя Петра I» [18], в которой приняли участие болгарские медиевисты М. Каймакамова, Г. Николов, А. Николов и Н. Хрисимов. Годом позже в Кракове была опубликована коллективная монография М. Лешки, 3. Бжозовской и Кирилла Маринова «Петр I Святой, царь болгарский (ок. 912-969). Мария Лакапина, царица болгарская (ок. 912-963)» [6], предназначенная польскому читателю. Сербско-визан- 
тийская тематика представлена в исследованиях лодзинских историков книгой Блажея Шефлиньского о «трех обличьях» св. Саввы Сербского - исторической фигуры, самопрезентации и литературного персонажа [17].

С созданием в середине 1990-х гг. в Лодзи кафедры славянской филологии во главе с языковедом-болгаристом проф. Малгожатой Корытковской и с приходом в ее состав (а затем и на заведование) Георгия Минчева, выпускника Софийского университета св. Климента Охридского и видного филолога-медиевиста, получило новый импульс развития историко-филологическое направление византийско-славянских исследований, стержнем которого стали исследования православной славянской духовной культуры, а в их рамках - канонических, псевдоканонических и апокрифических текстов, в значительной части созданных в рамках средневековой болгарской книжности. Направление заявило о себе двумя международными научными конференциями «Славянская апокрифическая библия» (2006 и 2009 гг.), посвященными ветхозаветным и новозаветным славянским ${ }^{1}$ апокрифам, и изданиями их материалов, осуществленными в сотрудничестве с другим крупным центром польской палеославистики - Краковским университетом.

В 2007 г. на кафедре славянской филологии было создано отделение палеославистики и народной культуры, в которое помимо Г. Минчева вошли выпускники университета Лодзи Малгожата Сковронек, Зофия Бжозовска и Иван Петров. Визитной карточкой нового исследовательского направления стали монографии и сборники, объединяющие исследовательские тексты с комментированными изданиями источников в оригиналах и переводах на польский язык. Так, ей было предпринято издание источников о жизни и деятельности киевской княгини Ольги [3]. Еще один труд 3. Бжозовской, также вышедший в этой серии, посвящен образу Софии-Премудрости Божьей в византийско-славянской культуре [4]. В 2019 г. исследовательница совместно с И. Петровым опубликовала древнерусский текст и польский перевод старшей редакции I Новгородской (по терминологии А.А. Гиппиуса и Т.В. Гимона [1] - Новгородской владычной) летописи, ведшейся при ка- федральном храме Великого Новгорода св. Софии - и сохранившейся в списке 786 Синодального собрания Государственного исторического музея середины XIV в. [12]. Молодой ученый Ян Миколай Вольски выпустил в серии Byzantina Lodziensia монографию о болгарской монашеской культуре позднего Средневековья [1], приложением к которой стали тексты среднеболгарского Номоканона по рукописи № 1060 Церковного историкоархивного музея в Софии в оригинале и переводе на польский язык.

В понимании лодзинских ученых-славяноведов палеославистические исследования по определению междисциплинарны и наднациональны, а также должны сочетать текстологический и языковедческий анализ средневековых текстов с исследованиями их общекультурного контекста, прежде всего, литургики, искусства и фольклора. Примеры реализации такого подхода - докторские диссертации Г. Минчева о функционировании православных канонических текстов в сакральном искусстве и фольклоре балканских славян [11] и его ученицы М. Сковронек - об образе Архангела Михаила в культуре православных славян на Балканах [13].

Синергия византологического и палеославистического направлений выразилась в создании в Лодзинском университете в 2011 г. междисциплинарного центра исследований средневекового Средиземноморья им. В. Церана. Центр, ядро которого составляют лодзинские византинисты и палеослависты, объединяет более ста ученых из многих стран мира и издает ежегодник «Studia Ceranea» (в 20112020 гг. вышло 10 томов, с 2019 г. издание индексируется в международной базе данных SCOPUS). C 2015 г. под эгидой Центра публикуется серия научных трудов «Series Ceranea», к настоящему времени насчитывающая пять томов. В 2019-2020 гг. были проведены два международных научных форума «Colloquia Ceranea» (коллоквиум 2020 г. - в удаленном формате). Материалы первого из них опубликованы в IX выпуске Studia Ceranea за 2019 год.

Методы. Задачи нашего обзора - в рамках научных интересов и компетентности автора дать общую характеристику формирования лодзинской школы византийско-славян- 
ских исследований в текущем веке; охарактеризовать в порядке их выхода в свет тематику и методологию опубликованных в 2015-2020 гг. под эгидой кафедр истории Византии и славистики, а также Центра им. В. Церана университета Лодзи монографических трудов, а также оценить их значение на фоне современного состояния мировой византинистики и болгаристики и дальнейшие перспективы развития.

В силу ограниченности объема рецензии основной применяемый нами метод - аннотирование с отдельными критическими замечаниями. Поскольку в большинстве рецензируемых работ не заявлены вербально применяемые их авторами методы, мы стремимся выявить методологические особенности трудов лодзинских исследователей путем их сравнения между собой и с аналогичными им по тематике современными научными работами.

Анализ. Открывший серию «Series Ceranea» сборник славянских источников о средневековых дуалистических ересях [16] включает комментированные издания пятнадцати отрывков текстов X-XV вв., созданных в Болгарии, Сербии и Древней Руси, в оригиналах и переводах на польский язык. Книгу открывает статья Г. Минчева «Славянские антиеретические тексты как источники для изучения дуалистических ересей на Балканах», содержание которой существенно выходит за рамки обычного предисловия. Автор придерживается подхода к средневековым ересям православных Балкан как к гетерогенному, но внутренне связанному комплексу умозрительных представлений и религиозных практик, восходящих к восточным религиозным учениям и движениям - манихейству, мессалианству и павликианству. Богомильство, представляемое в славянских источниках как «новоявленная ересь», по мнению Минчева, сочетало доктринальные представления предшествовавших ему еретических учений с элементами иконоборчества, «потрясавшего византийскую ойкумену в VIII-IX вв.» [16, s. 29]. Представленные в сборнике тексты автор относит к восьми группам источников: антиеретическим трактатам (Беседа против еретиков пресвитера Косьмы); церковно-правовым текстам (болгарский и сербский Синодики в Неделю православия, Кормчие книги); агиографическим сочинениям («Житие Фео- досия Тырновского» патриарха Каллиста и «Житие Иллариона Мегленского» патриарха Евфимия Тырновского); кратким описаниям ереси в литургической и монастырской книжности (служебники и уставы); усвоенным церковью псевдоканоническим книгам («Историческая палея»), «литературным текстам, бытовавшим на границе между канонической и неканонической литературами» («Слово о происхождении павликиан»); свидетельствам о еретиках в контексте богословских рассуждений («Шестоднев» Иоанна Экзарха Болгарского). В третьем параграфе вступительной статьи Г. Минчев оправданно ставит вопрос о взаимоотношениях антиеретической и еретической книжности, указывая на обилие общих мест и литературных штампов, перешедших в славянские тексты из византийских греческих источников, прежде всего «Догматического всеоружия» Евфимия Зигавина и «Алексиады» Анны Комнины, а также нашедших отражение в латинской «Тайной книге богомилов». В статье подробно изложены доктринальные положения богомильства. Вошедшие в книгу тексты выполнены по новейшим научным изданиям и в ряде случаев впервые вводятся в оборот как источники по истории богомильства. Так, четырнадцать отрывков из «Шестоднева» Иоанна Экзарха косвенно подтверждают высокий авторитет его автора как борца с ересями, упоминаемый Косьмой Пресвитером. Вместе с этим важно вспомнить, что в другой компендиум Иоанна Экзарха - «Небеса» - не вошли именно антиеретические главы его прототипа - «Точного изложения православной веры» св. Иоанна Дамаскина. На фоне пространных текстов «Беседы против еретиков» Косьмы Пресвитера, Синодика болгарской церкви и житий св. Иллариона Мегленского, Феодосия Тырновского и Ефрема Сербского менее информативными выглядят небольшие фрагменты Скитского устава, Номоканона Псевдо-Зонары и других канонических текстов, но именно они придают сборнику как коллекции славянских известий о богомильстве и других дуалистических ересях новизну и позволяют составить более точное представление об источниках приводимых ими сведений. Достойно открыв новую серию научных публикаций Центра им. В. Церана, книга, на наш взгляд, высту- 
пила моделью для других работ по византийско-славянской культурной истории, сочетающих обобщающее исследования с научной публикацией, пополняющейся в основном рукописным материалом.

Книга Я. Вольского [20], написанная по материалам защищенной годом ранее докторской диссертации, содержит очерки монастырской жизни в Болгарии XIII-XIV вв. и воспроизведение по рукописному тексту относящихся к теме отрывков хранящегося в Болгарии так называемого Архивского номоканона XIV века ${ }^{2}$. Ее открывает источниковедческий обзор, включающий как нарративы, так и характеристики сохранившихся рукописей и других свидетельств состава монастырских библиотек. Начав обзор с немногих сохранившихся описей греческих и славянских книг в монастырях XIII-XIV вв., автор продолжает его рекомендациями монастырских уставов и завершает анализом присутствия и цитирования отдельных сочинений в некоторых среднеболгарских рукописях. Во второй части обзора Я. Вольский обращается к нормативным текстам, среди которых особо выделены указанный выше Архивский номоканон и канонические указания Берлинского сборника начала XIV века. Третью часть обзора составили краткие характеристики житий болгарских патриархов Иоакима и Евфимия, подвижников Григория Синаита, Феодосия Тырновского, Ромила Бдинского и созданных в XIII-XIV вв. житий болгарских монахов более раннего времени, а завершает обзор источников краткая справка о сохранившихся грамотах государей второго Болгарского царства монастырям. На наш взгляд, автор мог бы почерпнуть дополнительную информацию из так называемых монастырских сборников смешанного состава, но привлек к анализу лишь Берлинский сборник начала XIV века. Наблюдения за изменениями их репертуара, наличием текстов, лежащих на грани между каноническими и неканоническими сочинениями, а иногда и за ней, распространение в монастырских сборниках со второй половины XIV в. аскетических текстов (переводы «Диоптры» Филиппа Монотропа и трудов, приписываемых Дионисию Ареопагиту и пр.), расширяют возможность судить о духовных интересах монашествующих и их эволюции.
Первые две части второго, исследовательского раздела «Культура монашества» посвящены соответственно идеалам монашеской жизни (отчуждению от мира, покаянию и молитве) и ее «стилям»: общежительному, отшельническому, «полууединенному» исихастскому и особножительному, который наряду с упоминаемым в Архивском номоканоне «самоволием» отнесен к аномальным. Третья часть раздела, по объему равная двум первым, трактует о «месте монашеского движения в общественной жизни средневековой Болгарии XIII и XIV вв.» и могла бы составить отдельную часть книги. В ней выделены параграфы о жизнеописаниях святых мужей; роли монахов как хранителей и защитников государства, их заботе о спасении душ и роли монастырей как центров хозяйственной, литературной и образовательной деятельности. Книгу завершает краткий вывод о роли монашества как сообщества «профессиональных христиан», выполнявших важнейшую в средневековом обществе функцию «молитвенного делания», что формировало их особый статус в глазах средневековых болгар помимо других значимых функций в различных сферах общественной жизни. Если автор в дальнейшем сумеет развить его на более широкой источниковой основе и в рамках ясно представляемой и внятно сформулированной методологии, его дальнейшие исследования, несомненно, смогут занять важное место в историографии культуры болгарского Средневековья.

Третьим и четвертым томами в серии «Series Ceranea» вышли на английском и польском языках монографии М. Сковронек о втором славянском переводе византийской компиляции ветхозаветных библейских сказаний, известной как Историческая Палея. В первой из них [14] наряду с критическим изданием текста памятника по восьми из десяти известных на сегодняшний день южнославянских списков XIV-XVII вв. автор характеризует особенности рукописной традиции, историю ее изучения, содержание памятника и отличия второго славянского перевода от предшествующих. Вторая книга «Библейские повествования. Палея историческая в византийско-славянской традиции» [15] помимо этого включает исследования происхождения и 
содержания цитат из Ветхого Завета, способов конструирования сакральной истории, а также вошедших во второй перевод поэтических произведений и анафем. Особое значение имеет приложение, включающее текстологическую стемму, сопоставление названий глав в различных списках, сравнение текстов Покаянного канона, тексты, составляющие «конвой» списков Исторической Палеи в различных сборниках (цикл мистагогических и богословских текстов, имеющийся в трех списках); историю Сусанны; слово о происхождении Святого Семейства и другие сказания на ветхозаветные темы.

Переходя непосредственно к средневековой болгарской исторической тематике, мы отдаем себе отчет, что впечатления читателя не всегда совпадают с результатами реализации авторского замысла и не могут быть основой для оценки такового, особенно если он не заявлен в научной работе вербально и недвусмысленно. В предисловии к вышедшему через четыре года после лодзинского издания болгарскому переводу книги о Симеоне Великом (893-927) [2, с. 9-11] М. Лешка предложил своим новым читателям взглянуть на образ первого болгарского царя «под другим углом», представив его и его деяния результатом многолетнего политического и культурного взаимодействия Болгарии с Восточной Римской империей. В основе такого подхода находятся как характер и содержание источниковой основы работы (уместно напомнить, что написанию книги о Симеоне предшествовала монография М. Лешки об образах болгарских государей в византийских источниках VIII-XII вв.), так и характерное для историка Византии представление о цивилизующей роли Константинополя в развитии народов и государств востока Европы. В то же время автор строго соблюдает грань между гипотезой и домыслом, последовательно ставя под сомнение или отвергая имеющиеся в научной литературе предположения, не находящие подтверждений в источниках - о сакральном значении отстранения Борисом-Михаилом от власти старшего сына ВладимираРасате, соборном избрании тридцатилетнего Симеона государем в 893 г., решении на том же соборе перенести столицу в Преслав и пр. История правления Симеона целиком поме- щена в контекст болгаро-византийских отношений, рассматриваемых на примерах болгаро-византийской войны 893-896 гг; ; ее «странного» продолжения в 897-904 гг;; обострения отношений в ходе династического кризиса в Константинополе в 912-913 гг.; перемирия в сентябре 913 г., закрепленного так называемой «коронацией» Симеона патриархом Николаем Мистиком; возобновления конфронтации в 914-924 гг., когда Симеону удалось разгромить войска императора Романа Лакапина 20 августа 917 г. под Анхиало, но он не сумел закрепить военные успехи, вследствие чего очередные переговоры с Византией в 924 г. не дали значимого результата. М. Лешка оправданно отвергает версию о новом походе Симеона на Константинополь в 927 г., подготовка к которому была якобы прервана неожиданной смертью болгарского царя, аргументированно видя результаты византийской политики Симеона в «вечном мире» и династическом браке, заключенными Константинополем с его сыном Петром. Две последние главы книги составляют пространное заключение к книге. Целями болгарского государя в его войнах с Византией признаются достижение политического равновесия между Болгарией и Византией через равное достоинство государств и церквей и, как следствие, установления дальнейших мирных отношений. Отмечая, что войны Симеона велись преимущественно на территории империи, автор указывает, что исторические свидетельства о Симеоне в Константинополе и Преславе соответственно сохранили два образа: военного вождя и хитрого политика у византийцев и мудрого правителя, покровителя книжности у болгар. Строго академический тон и скрупулезный анализ источников выгодно отличают оценку польским ученым Симеона и его деятельности и от полных суперлативами популярных биографических очерков, и от масштабных историографических схем «Симеонова века» или «Преславской цивилизации».

На наш взгляд, труды и ученики М. Лешки дали импульс масштабному исследовательскому проекту комплексного изучения истории первого Болгарского царства, началом которого стала вышедшая в свет в 2015 г. в издательстве Польской Академии наук коллективная монография под редакцией М. Леш- 
ки и К. Маринова «Болгарское царство. Политика - общество - хозяйство - культура. 866-971» [10]. Книга состоит из двух частей, посвященных политической истории первого Болгарского царства (авторы оговаривают свое понимание этого термина, не распространяющееся на правление Самуила), и развитию в его рамках государства, общества, экономики и культуры. Обращает внимание критическое - а временами остро полемическое изложение фактов политической истории в контексте посвященных им научных трудов. Объем примечаний в книге почти равен тексту самого исследования, критические замечания даны в корректном, но твердом тоне. Очерк политической истории начинается правлением Бориса-Михаила, первые датированные сведения о котором относятся к 852 г., и обстоятельствами принятия болгарским князем христианства, которое М. Лешка вслед за Т. Василевским относит к 866 году. Эта дата, вынесенная в заглавие труда, служит точкой отсчета истории Болгарского царства, причем автор подтверждает источниками и другое предположение своего польского предшественника - о том, что выступление болгарской знати против Бориса предшествовало крещению, а не последовало за ним. В политический раздел вошли и основные выводы книги автора о царствовании Симеона, которого он называет «творцом первого Болгарского царства». Главы о правлениях его сына царя Петра (927-969) и внука Бориса II (969-971), написанные М. Лешкой совместно с К. Мариновым, завершает вывод, что походы Иоанна Цимисхия с их триумфальным завершением в Константинополе - развенчанием потомка и соименника крестителя Болгарии Бориса II - первоначально не имели столь масштабной цели, и император решил положить конец политическому бытию Болгарского царства, воочию убедившись в его упадке, но не предполагая при этом, что оставшиеся вне зоны военных действий юго-западные земли могут стать очагом многолетнего сопротивления болгар византийскому завоеванию. Вторая часть книги открывается разделом о государстве и обществе, также написанным М. Лешкой и К. Мариновым. В него вошли разделы о монархе, центральных и провинциальных властях, столицах государства - Плис- ке и Преславе. В отдельный параграф вынесен вопрос о так называемых государственных «соборах», где авторы констатируют отсутствие сведений источников об их постоянном функционировании в системе государства. Завершают раздел очерки К. Маринова о вооруженных силах и оборонительной системе первого Болгарского царства. Второй раздел посвящен роли церкви. Обращаясь в первом параграфе к вопросу о статусе болгарской церкви, М. Лешка критически рассматривает существующие в болгарской научной литературе гипотезы и приходит к выводу, что оформление самостоятельной церковной организации завершилось установлением патриархии лишь в начале царствования Петра. Я. Вольский во втором параграфе пишет о распространении различных монастырских практик в Преславе, где существовали крупные монастыри, и в отдаленных горных обителях, где задолго до св. Иоанна Рильского распространилось отшельничество, а в четвертом - рассматривает строительство храмов и монастырей. Между этими текстами помещен параграф о богомильстве, в котором автор, участвовавший в переводе текстов для издания Г. Минчева, критически относится к попыткам поисков в этом движении антигосударственных и социальных мотивов. Написанный К. Мариновым третий раздел о хозяйстве раннесредневековой Болгарии акцентирует условия развития, виды хозяйственной деятельности и коммуникационную инфраструктуру ее экономики. Автор замечает, что избрал элементы хозяйства, которые считает репрезентативными, но, на наш взгляд, раздел вполне завершен и репрезентативен. Его следует считать серьезным вкладом в историографию первого Болгарского царства, особенно с учетом ухода в последние тридцать лет социально-экономической тематики на второй план и в болгарской, и мировой медиевистике. Последний, четвертый, раздел книги о духовной культуре и литературе Болгарии конца IX - X в. принадлежит Я. Вольскому и в основных чертах следует общим трудам болгарских и отчасти российских ученых по данной тематике, включая выделение Преславской и Охридской литературных школ, которым посвящены два составляющие его параграфа. Книга завершается лаконичным заключением, что 
именно плоды краткого, но бурного развития первого Болгарского царства после принятия христианства под руководством основанной Борисом-Михаилом династии, а также историческая память болгар об их свершениях создали прочную основу для сохранения, восстановления и дальнейшего развития болгарской средневековой государственности.

Наиболее крупный труд лодзинских ученых в области византийско-болгарских исследований на сегодняшний день является результатом реализации М. Лешкой, 3. Бжозовской, К. Мариновым и Я. Вольским масштабного проекта, посвященного средневековой Болгарии в эпоху царя Петра (927-969) [18]. В нем приняли участие ученые-медиевисты двух болгарских университетов - Софийского и Великотырновского - М. Каймакамова, А. Николов и Н. Хрисимов. Монография о болгарском государстве в царствование Петра (927-969) - первое в историографии полномасштабное и комплексное исследование наименее исследованной эпохи в истории средневековой Болгарии. В изданной на английском языке в серии «Byzantina Lodziensia» (т. XXXIV) книге - три раздела, посвященные событиям и структурам в Болгарии эпохи Петра, а также их отражению в средневековых источниках и историографии. Книгу в целом открывает краткий обзор источников и литературы, а две вступительных главы первого раздела повествуют о внутреннем и внешнем контекстах восхождения Петра на царский трон. Они написаны М. Лешкой на основе его прежних исследований и глубокого анализа современной болгарской историографии, включая работы на полях академического мэйнстрима. Третья глава - «Мир», - написанная Лешкой в соавторстве с К. Мариновым, посвящена обстоятельствам заключения и условиям мирного договора с Византией 927 г., который конституировал положение Болгарии в ее отношениях с Византией. Отдельное значение придается брачному соглашению, установившему статус болгарского царя в «семье государей», которой представлялась из Константинополя византийская ойкумена. Важность брачного союза подчеркивается включением главы 3. Бжозовской о византийской супруге царя Петра Марии Лакапине, где, как и в изданной годом ранее монографии, проводится параллель с византийской супругой киевского князя Владимира Святого Анной. По мнению автора, обе константинопольские принцессы выступали символами имперской санкции власти их мужей, не принимая участия в государственном управлении. Вторую половину раздела составляют написанные М. Лешкой и К. Мариновым главы V-VIII о внутренних и внешнеполитических делах в царствование Петра, кризисе болгаро-византийских отношений после смерти Марии (963969), последних годах правления болгарского царя и коротком царствовании его сына Бориca II (969-971). Запомнившееся болгарам, с одной стороны, как годы изобилия в правление святого царя, а с другой - как время появления богомильской ереси, царствование Петра завершилось «ратными бедами» и крушением государственности, созданной усилиями трех поколений первой династии христианских правителей раннесредневековой Болгарии. Второй раздел - «Структуры» - состоит также из восьми глав, две из которых - о повседневной жизни Болгарии эпохи царя Петра и организации государственной власти написаны болгарскими историками Н. Хрисимовым и Г. Николовым, а еще одна - о культуpe - совместно 3. Бжозовской и А. Николовым. Основное содержание главы составляют очерки К. Маринова о географической среде и геополитике Болгарского царства Петра, его хозяйственной жизни, вооруженных силах и военных конфликтах с Византией, в которых особую роль играл главный для Константинополя геополитический маркер Болгарии - горы с их труднопроходимыми перевалами и воинственными жителями. В главе о церкви М. Лешка связывает с правлением Петра оформление ее статуса и внутренней организации, а Я. Вольский пишет о состоянии монашества и развитии богомильства. В завершающей раздел главе о культуре 3. Бжозовская представила церковную архитектуру и искусство, преодолевая неизбежную описательность анализом сведений письменных источников о болгарских иконах и храмовых росписях этого времени. Третий раздел - «Интерпретации» - составляют четыре главы, одна из которых - о почитании царя Петра в болгарских землях под властью Византии написана профессором Софийского универси- 
тета М. Каймакамовой. Очерки М. Лешки об образе царя Петра в средневековых болгарских, византийских и латинских источниках и К. Маринова об исторических сведениях в «Слове о мире с болгарами», атрибутируемом византийскому сановнику Феодору Дафнопату, в общих чертах повторяют ранее вышедшие по-польски публикации, в то время как написанный специально для книги Я. Вольским подробный обзор историографии эпохи царя Петра охватывает всю литературу вопроса от Мавро Орбини до современных авторов и представляет, наряду с внушительным списком литературы, особый интерес для внимательного читателя. Краткое, но емкое заключение подчеркивает, что именно в правление Петра средневековая Болгария окончательно отстроила свою государственность и сумела ее защитить от многочисленных врагов, но была предана своим южным соседом и долговременным внешнеполитическим партнером - Византией. Петр последними усилиями смог отстоять свою страну от спровоцированного Константинополем похода Святослава Игоревича, но его наследники понесли военное поражение от Константинополя и были вынуждены возвратить Второму Риму полученные Петром царские инсигнии вместе с символом небесной защиты их столицы - храмовой иконой Богоматери. Однако именно Петр запомнился потомкам как последний независимый государь первого Болгарского царства, а его имя стало символом государства в долгие десятилетия пребывания болгарских земель в составе Византийской империи.

Еще одна форма представления результатов исследований и интеграции с коллегами из других польских и зарубежных научных центров - тематические сборники, примером которых является вышедший в свет в текущем году том «Призрак Магомета, тень Самуила», посвященный средневековым представлениям других религий и культур о Византийской империи [19]. В книгу вошли статьи по докладам двух секций Шестого конгресса польских медиевистов, состоявшегося в 2018 г. во Вроцлаве. Интересующая нас тематика представлена в этом сборнике статьей 3. Бжозовской о влиянии византийских авторов на историческое сознание восточных и южных славян на примере сказания о Мухаммеде в «Истории павликиан» Петра Сицилийского, двумя работами М. Лешки - об образе болгарского правителя Самуила у византийских авторов и об отражении арабсковизантийского противостояния в $\mathrm{X}$ в. в хронике Константина Манассии; обзором текстов Палеи исторической против еретиков и мусульман М. Сковронек и статьей профессора кафедры истории Византии Лодзинского университета Терезы Волиньской о второй арабской редакции сказания о сирийском монахе Сергии (Саргисе) Бахире, одним из первых распознавшем в юном Мохаммеде посланного Богом пророка.

Результаты. На наш взгляд, рассмотренные выше работы лодзинских медиевистов существенно обогатили научную литературу по истории и культуре средневековой Болгарии, укрепив представление о ней как об интегральной части византийско-славянского сообщества IX-XV вв., уточнив важные факты политической истории Болгарии X в. и дав актуальные трактовки отдельным проблемам духовной культуры, социальной и экономической жизни, а также военной истории болгарского Средневековья. Рецензируемые работы отчетливо намечают основные направления, в которых развивается школа, выйдя за пределы публикации в основном квалификационных работ и реализуя масштабные исследовательские проекты, в том числе в сотрудничестве с зарубежными учеными. Рост числа англоязычных публикаций идет в тренде растущего взаимодействия с мировым ученым сообществом. Нарабатываются и уточняются методологические подходы к изучаемым темам, что придает научной школе византийско-славянских исследований Лодзинского университета своеобразие, необходимое для ее дальнейшего развития как одного из ведущих международных центров в области византийско-славянских и болгарских исследований. Зрелость научной школы определяется наличием и качеством исследовательской программы, сочетающей ясно сформулированные научные проблемы и совершенствование методологического инструментария для их разрешения в активном взаимодействии с ведущими мировыми центрами и учеными. Лодзинская школа, убедительно позиционируя 
себя в текущем столетии, набирает темпы на этом пути. Рецензенту остается искренне позавидовать той поддержке, которую она получает в своем университете, региональном и национальном сообществах, и пожелать коллегам новых достижений на этом пути.

\section{ПРИМЕЧАНИЯ}

1 Здесь и далее термин «славянский», как и в рецензируемых текстах, обозначает язык средневековых письменных источников без уточнения его изводов и редакций.

${ }^{2}$ Памятник является неполным списком распространенного на православных Балканах номоканона Псевдо-Зонары (Зинар). Название дано издателями фототипного текста рукописи по ее местонахождению в Церковно-историческом архивном институте при Священном Синоде Болгарской православной церкви в г. София, № 1060.

\section{СПИСОК ЛИТЕРАТУРЫ}

1. Гимон, Т. В. Новые данные по истории текста Новгородской первой летописи / Т. В. Гимон, А. А. Гиппиус // Новгородский исторический сборник. - 1999. - Вып. 7 (17). - С. 18-47.

2. Лешка, М. Симеон Велики и Византия. Из историята на българо-византийските отношения през 893-927 гг. / М. Лешка. - София : Агата-А, 2017. - 368 с.

3. Brzozowska, Z. Święta księżna kijowska Olga. Wybór tekstów źródłowych / Z. Brzozowska. - Łódź : Wydawnictwo Uniwersytetu Łódzkiego, 2014. - $220 \mathrm{~s}$.

4. Brzozowska, Z. Sofia - upersonifikowana Mądrość Boża. Dzieje wyobrażeń w kręgu kultury bizantyńsko-słowiańskiej / Z. Brzozowska. - Łódź : Wydawnictwo Uniwersytetu Łódzkiego, 2015. - $490 \mathrm{~s}$.

5. Brzozowska, Z. Maria Lekapene, Empress of the Bulgarians: Neither a Saint nor a Malefactress / Z. Brzozowska, M. Leszka. - Łódź : Wydawnictwo Uniwersytetu Łódzkiego, 2017. - 228 s.

6. Brzozowska, Z. Piotr I Święty, car bułgarski (ok. 912-969). Maria Lekapena, caryca bułgarska (ok. 912-963) / Z. Brzozowska, M. Leszka, K. Marinow. - Kraków : Avalon, 2018. - 347 s.

7. Ceran, W. Historia i bibliografia rozumowana bizantynologii polskiej (1800-1998). Vol. I-II / W. Ceran. - Łódź : Wydawnictwo Uniwersytetu Łódzkiego, 2001. - $786 \mathrm{~s}$.

8. Leszka, M. Wizerunek władców pierwszego państwa bułgarskiego w bizantyńskich źródłach pisanych (VIII - pierwsza połowa XII wieku) / M. Leszka. - Łódź : Wydawnictwo Uniwersytetu Łódzkiego, 2003. - 169 s.
9. Leszka, M. Symeon I Wielki a Bizancjum. Z dziejów stosunków bułgarsko-bizantyńskich w latach 893-927 / M. Leszka. - Łódź : Wydawnictwo Uniwersytetu Łódzkiego, 2013. - 368 s.

10. Leszka, M. Carstwo Bułgarskie. Polityka społeczeństwo - gospodarka - kultura, 866-971 / M. Leszka, K. Marinow. - Warszawa : Wydawnictwo Naukowe PWN SA, 2015. - 385 s.

11. Minczew, G. Święta księga - ikona - obrzęd. Teksty kanoniczne a ich funkcjonowanie w sztuce sakralnej i folklorze Słowian na Bałkanach / G. Minczew. - Łódź : Wydawnictwo Uniwersytetu Łódzkiego, 2003. - $223 \mathrm{~s}$.

12. Petrov, I. Latopis nowogrodzki pierwszy starszej redakcji. Unikatowy zabytek piśmiennictwa staroruskiego i jego polski przekład / I. Petrov, Z. Brzozowska. - Łódź : Wydawnictwo Uniwersytetu Łódzkiego, 2019. -436 s.

13. Skowronek, M. Świat cały ma Cię za obrońcę. Michał Archanioł w kulturze Słowian prawosławnych na Bałkanach / M. Skowronek. - Łódź : Wydawnictwo Uniwersytetu Łódzkiego, 2008. - 240 s.

14. Skowronek, M. Palaea Historica. The Second Slavic Translation - Commentary and Text / M. Skowronek. - Łódz: Wydawnictwo Uniwersytetu Łódzkiego, 2016. - 203 s.

15. Skowronek, M. Średniowieczne opowieści biblijne. Paleja historyczna w tradycji bizantyńskosłowiańskiej / M. Skowronek. - Łódz: Wydawnictwo Uniwersytetu Łódzkiego, 2017. -396 s.

16. Średniowieczne herezje dualistyczne na Bałkanach. Źródła słowiańskie / red. G. Minczew, M. Skowronek, J. M. Wolski. - Łódź : Wydawnictwo Uniwersytetu Łódzkiego, 2015. - 268 s.

17. Szefliński, B. Trzy oblicza Sawy Nemanjicia. Postać historyczna - autokreacja - postać literacka / B. Szefliński. - Łódź : Wydawnictwo Uniwersytetu Łódzkiego, 2016. - 342 s.

18. The Bulgarian State in 927-969: The Epoch of Tsar Peter I / ed. M. Leszka, K. Marinow. - Łódź : Wydawnictwo Uniwersytetu Łódzkiego, 2017. - 688 p.

19. Widmo Mahometa, cień Samuela. Cesarstwo bizantyńskie $w$ relacji z przedstawicielami innych religii i kultur (VII-XV wiek)/ red. Z. Brzozowska, M. Leszka, K. Marinow, T. Wolińska. - Łódź : Wydawnictwo Uniwersytetu Łódzkiego, 2020. - 380 s.

20. Wolski, J. M. Kultura monastyczna w późnośredniowiecznej Bułgarii / J. M. Wolski. - Lodz : Wydawnictwo Uniwersytetu Łódzkiego, 2018. - 232 s.

\section{REFERENCES}

1. Gimon T.V., Gippius A.A. Novye dannye po istorii teksta Novgorodskoy pervoy letopisi [New Data on the History of the Novgorod First Chronicle]. 
Novgorodskii istoricheskii sbornik [Novgorod historical articles], 1999, vol. 7 (17), pp. 18-47.

2. Leshka M. Simeon Veliki i Vizantiya. Iz istoriyata na blgaro-vizantiyskite otnosheniya prez 893-927 gg. [Simeon the Great and Byzantium. From the History of the Bulgarian-Byzantine Relations in 893-927]. Sofia, Agata-A Publ., 2017. 368 p.

3. Brzozowska Z. Święta księżna kijowska Olga. Wybór tekstów źródłowych [Saint Kievan Princess Olga. Selection of the Sources' Texts]. Łódź, Wydawnictwo Uniwersytetu Łódzkiego, 2014. 220 p.

4. Brzozowska Z. Sofia - upersonifikowana Madrość Boża. Dzieje wyobrażeń w kręgu kultury bizantyńsko-słowiańskiej [Sophia - the Personified God's Wisdom. A History of Presentations in the Circle of Byzantino-Slav Culture]. Łódź, Wydawnictwo Uniwersytetu Łódzkiego, 2015. 490 p.

5. Brzozowska Z., Leszka M. Maria Lekapene, Empress of the Bulgarians: Neither a Saint nor a Malefactress [Maria Lekapene, Empress of the Bulgarians: Neither a Saint nor a Malefactress]. Łódź, Wydawnictwo Uniwersytetu Łódzkiego, 2017. 228 p.

6. Brzozowska Z., Leszka M., Marinow K. Piotr I Święty, car butgarski (ok. 912-969). Maria Lekapena, caryca butgarska (ok. 912-963) [Peter I the Saint, Bulgarian Tsar. Maria Lekapena, Bulgarian Tsarina (ca 912-963)]. Kraków, Avalon, 2018.347 p.

7. Ceran W. Historia i bibliografia rozumowana bizantynologii polskiej (1800-1998). Vol. I-II [History and Annotated Bibliography of the Polish Byzantology (1800-1998)]. Lódź, Wydawnictwo Uniwersytetu Łódzkiego, 2001. 786 p.

8. Leszka M. Wizerunek władców pierwszego państwa bułgarskiego $w$ bizantyńskich źródłach pisanych (VIII - pierwsza polowa XII wieku) [Images of the first Bulgarian State Rulers $\left(8^{\text {th }}-\right.$ First Half of the $12^{\text {th }} \mathrm{cc}$.)]. Łódź, Wydawnictwo Uniwersytetu Lódzkiego, 2003. 169 p.

9. Leszka M. Symeon I Wielki a Bizancjum. Z dziejów stosunków bułgarsko-bizantyńskich w latach 893-927 [Symeon I the Great and Byzantium. From the history of the Bulgarian-Byzantine Relations]. Łódź, Wydawnictwo Uniwersytetu Łódzkiego, 2013. 368 p.

10. Leszka M., Marinow K. Carstwo Bułgarskie. Polityka - społeczeństwo - gospodarka - kultura, 866-971 [Bulgarian Tsardom. Politics - Society Economics - Culture]. Warszawa, Wydawnictwo Naukowe PWN SA, 2015. 385 p.

11. Minczew G. Święta księga-ikona-obrzęd. Teksty kanoniczne a ich funkcjonowanie w sztuce sakralnej i folklorze Stowian na Batkanach [Holy Scripture - Icon - Rite. Canonic Texts and their Functioning in the Sacral Art and Folklore of Slavs at the Balkans]. Łódź, Wydawnictwo Uniwersytetu Łódzkiego, 2003. 223 p.

12. Petrov I., Brzozowska Z. Latopis nowogrodzki pierwszy starszej redakcji. Unikatowy zabytek piśmiennictwa staroruskiego i jego polski przektad [Novgorod First Chronicle. A Unique Monument of Old Russian Letters and its Polish Translation]. Łódź, Wydawnictwo Uniwersytetu Łódzkiego, 2019. 436 p.

13. Skowronek M. Świat caty ma Cię za obrońcę. Michat Archaniol $w$ kulturze Stowian prawostawnych na Batkanach [The Entire World Has You as Protector]. Łódź, Wydawnictwo Uniwersytetu Łódzkiego, 2008. 240 p.

14. Skowronek M. Palaea Historica. The Second Slavic Translation - Commentary and Text. Łódz, Wydawnictwo Uniwersytetu Łódzkiego, 2016. 203 p.

15. Skowronek M. Średniowieczne opowieści biblijne. Paleja historyczna $w$ tradycji bizantyńskosłowiańskiej [Medieval Biblical Tales. Historical Palaia in the Byzantine-Slav Tradition]. Łódz, Wydawnictwo Uniwersytetu Łódzkiego, 2017. 396 p.

16. Minczew G., Skowronek M., Wolski J.M., eds. Średniowieczne herezje dualistyczne na Batkanach. Źródła słowiańskie [Medieval Dualistic Heresies an the Balkans. The Slavonic Sources]. Łódź, Wydawnictwo Uniwersytetu Łódzkiego, 2015. 268 p.

17. Szefliński B. Trzy oblicza Sawy Nemanjicia. Postać historyczna - autokreacja - postać literacka [The Three Images of Sava Nemanich - Self-Image Literary Person]. Łódź, Wydawnictwo Uniwersytetu Łódzkiego, 2016. 342 p.

18. Leszka M., Marinow K., eds. The Bulgarian State in 927-969: The Epoch of Tsar Peter I. Łódź, Wydawnictwo Uniwersytetu Lódzkiego, 2017. 688 p.

19. Brzozowska Z., Leszka M., Marinow K., Wolińska T., eds. Widmo Mahometa, cień Samuela. Cesarstwo bizantyńskie w relacji z przedstawicielami innych religii $i$ kultur (VII-XV wiek) [Image of Muhammad, Shadow of Samuel. Byzantine Empire in Connection with Images of Other Regions and Cultures]. Łódź, Wydawnictwo Uniwersytetu Łódzkiego, 2020. 380 p.

20. Wolski J.M. Kultura monastyczna w późnośredniowiecznej Bułgarii [The Monastic Culture in Late Medieval Bulgaria]. Lodz, Wydawnictwo Uniwersytetu Łódzkiego, 2018. 232 p. 


\section{Information About the Author}

Dmitry I. Polyvyannyy, Doctor of Sciences (History), Professor, Head of the Research and Educational Center for the Integration of Science and Education, Ivanovo State University, Ermaka St, 39, 153025 Ivanovo, Russian Federation, dipol53@mail.ru, https://orcid.org/0000-0003-3680-5508

\section{Информация об авторе}

Дмитрий Игоревич Полывянный, доктор исторических наук, профессор, руководитель научно-образовательного центра интеграции науки и образования, Ивановский государственный университет, ул. Ермака, 39, 153025 г. Иваново, Российская Федерация, dipol53@mail.ru, https://orcid.org/0000-0003-3680-5508 